\title{
OPEN Association of self-rated health with chronic disease, mental health symptom and social relationship in older people
}

\author{
Hongling Yang ${ }^{1,7}$, Qin Deng ${ }^{2,7}$, Qingshan Geng ${ }^{3,7}$, Yanfei Tang ${ }^{4,7}$, Jun $\mathrm{Ma}^{5}$, Weitao Ye ${ }^{5}$, \\ Qiangsheng Gan $^{5}$, Rehemutula Rehemayi ${ }^{5}$, Xiaoli Gao ${ }^{6}$ \& Chunyan Zhu ${ }^{5 凶}$
}

Chronic disease, mental health symptoms and poor social relations are reported common causes for poor self-rated health in older people. To assess the co-occurrence rate of chronic diseases, poor mental health and poor social relationships in older people, and determine their association with self-rated health. 6,551 older people in Zhongshan, China, participated a large health surveillance program were randomly selected and questioned about their $\mathrm{SRH}$, chronic conditions, mental health symptoms and social relationships. The association between self-rated health and chronic conditions, poor mental health, social relationships, and their co-occurrence were analyzed. $56.4 \%$ of participants reported poor self-rated health. $39.1 \%$ experienced at least one chronic disease. $29.0 \%$ experienced one or more mental health symptoms; $19.5 \%$ experienced at least one poor social relationship. $7.8 \%$ had co-occurrence of chronic diseases, mental health problems, and poor social relationships. Logistic regressions showed that poor self-rated health was associated with chronic diseases, poor mental health, poor social relationships and their co-occurrence. The findings indicate the importance of managing chronic disease, poor mental health and poor social relationships for older people.

Self-rated health is a commonly used measure for subjectively perceived health ${ }^{1}$. It provides an overview of an individual's health status and it is associated with future health outcomes, including mortality and subclinical aspects of personal health ${ }^{1,2}$.

Self-rated health is associated with various health predictors and outcomes, such as sociodemographic characteristics, lifestyle factors, physical health status, mental health status, and functional limitations ${ }^{3}$. Self-rated health decreases with physical well-being, and significant differences are observed between those with the best and worst levels of social well-being ${ }^{4}$. A study carried out among older people in Shanghai showed that the main determinants of self-rated health among older people included living conditions, health risk behavior, social support, health status, and the economic status of the neighborhood ${ }^{5}$.

Previous research has largely focused on the effect of individual predictors of self-rated health, despite the high prevalence of their co-occurrence among older people. The ageing process results in an increase in the comorbidity of chronic diseases, disability, reduced levels of functioning, and mental health problems. It was reported that more than $50 \%$ of adults aged 55 years and older had at least two chronic conditions ${ }^{3}$, and somatic complaints are highly associated with mental health symptoms ${ }^{6}$.

In China, the number of elderly people is increasing. Progressive ageing has a profound impact on the physical, social and mental health of the population. Chronic diseases, poor mental health and poor social relationships affect older people ${ }^{8}$. Among the elderly over the age of $60,23.8 \%$ had poor mental health status and $68.7 \%$ suffered from two or more chronic diseases ${ }^{8}$. The high prevalence of chronic diseases, poor mental health and poor social relations among older people in China raises questions as to whether, and to what extent, these conditions account for their poor self-rated health.

${ }^{1}$ Guangzhou Women and Children's Medical Centre, Guangzhou Medical University, Guangzhou, China. ${ }^{2}$ Pharmacy Department, Dongguan Qishi Hospital, Dongguan, China. ${ }^{3}$ Guangdong General Hospital, Guangdong Academy of Medical Science, Guangzhou, China. 'Zhongshan Dachong Community Health Service Centre, Zhongshan, China. ${ }^{5}$ Department of Prevention Medicine, School of Public Health, Guangzhou Medical University, Guangzhou, China. ${ }^{6}$ Faculty of Dentistry \& Saw Swee Hock School of Public Health, National University of Singapore, Singapore, Singapore. ${ }^{7}$ These authors contributed equally: Hongling Yang, Qin Deng, Qingshan Geng and Yanfei Tang. ${ }^{\boxplus}$ email: zchyan@163.com 


\begin{tabular}{|c|c|c|}
\hline & n & $\%$ \\
\hline \multicolumn{3}{|l|}{ Age (year) } \\
\hline Mean \pm SD & $70.2 \pm 8.1$ & \\
\hline Min-max & $60-104$ & \\
\hline \multicolumn{3}{|l|}{ Age group (year) } \\
\hline $60-69$ & 3549 & 54.2 \\
\hline $70-79$ & 2067 & 31.5 \\
\hline$\geq 80$ & 935 & 14.3 \\
\hline \multicolumn{3}{|l|}{ Sex } \\
\hline Male & 3539 & 54.0 \\
\hline Female & 3012 & 46.0 \\
\hline \multicolumn{3}{|l|}{ Marital status ${ }^{*}$} \\
\hline Married & 4727 & 72.2 \\
\hline Unmarried & 125 & 1.9 \\
\hline Separated /widowed/divorced & 1694 & 25.9 \\
\hline \multicolumn{3}{|l|}{ Education level ${ }^{*}$} \\
\hline Below primary school & 1904 & 29.1 \\
\hline Primary & 3464 & 53.0 \\
\hline Secondary and higher & 1172 & 17.9 \\
\hline \multicolumn{3}{|l|}{ Living arrangement } \\
\hline With other person(s) & 5935 & 90.6 \\
\hline Alone & 616 & 9.4 \\
\hline \multicolumn{3}{|l|}{ Economic conditions } \\
\hline Good & 2467 & 37.6 \\
\hline Fair & 3437 & 52.5 \\
\hline Poor & 647 & 9.9 \\
\hline \multicolumn{3}{|l|}{ Housing conditions } \\
\hline Good & 3757 & 57.3 \\
\hline Fair & 2540 & 38.8 \\
\hline Poor & 254 & 3.9 \\
\hline
\end{tabular}

Table 1. Socio-demographic characteristics of respondents $(n=6551) .{ }^{\star}$ Data of some participants were missing.

Concrete evidence indicates that the risk of poor self-rated health increases with the number of chronic diseases ${ }^{9}$, mental health symptoms ${ }^{10}$, and social support ${ }^{11}$. However, there is a lack of research concerning the association between self-rated health and the co-occurrence of chronic diseases, mental health symptoms, and poor social relationships, especially among older people. Furthermore, little attention has been paid to the correlation between chronic diseases, mental health symptoms, and poor social relationships in terms of self-rated health among community-dwelling older people in China.

Zhongshan is a city that is located at the southern tip of the Chinese mainland and the eastern bank of the mouth of the Pearl River. In less than 30 years, Zhongshan has grown from a traditional agricultural town into a modern metropolis ${ }^{12}$. Older people in Zhongshan can be regarded as a typical population that has aged under the reform and opening-up policy in China, which started in the late 1970s. Urbanization and subsequent changes in lifestyles, family patterns, and social relationships are likely to have profound impacts on their health.

The current study, centered on a population-based sample of older adults in Zhongshan, South China, and it aimed to (i) determine the rate of chronic diseases, mental health symptoms and poor social relationships, as well as their co-occurrence, and (ii) to investigate the association between these factors and self-rated health.

\section{Results}

Sample characteristics. In total, 6,551 older people participated in this study. The mean age was 70.2 (S.D. $=8.1$ ) years. The majority of the participants $(82.0 \%)$ was below primary school or had only completed primary education, while $9.4 \%$ lived alone, and $37.6 \%$ and $57.3 \%$ reported good economic conditions and housing conditions, respectively (Table 1 ).

Among the 6,551 participants, $56.4 \%$ reported poor self-rated health; $28.6 \%$ suffered from one chronic disease and $10.5 \%$ reported two or more chronic diseases; $29.0 \%$ experienced one mental health symptom and $44.3 \%$ reported two or more symptoms; $19.5 \%$ experienced at least one type of poor social relationship; $34.8 \%$ experienced two co-occurrent conditions (e.g., chronic disease and/or mental health symptom and/or poor social relationships) and 7.8\% reported three co-occurrent conditions (chronic disease, mental health symptoms, and poor social relationships). Approximately half of participants (47.7\%) reported fair or poor sleep; $18.4 \%$ required medication to support their daily life; and 66.8\% experienced at least one limitation in their activities (Table 2). 


\begin{tabular}{|c|c|c|}
\hline & n & $\%$ \\
\hline \multicolumn{3}{|l|}{ Self-rated health } \\
\hline Good & 2853 & 43.6 \\
\hline Poor & 3698 & 56.4 \\
\hline \multicolumn{3}{|l|}{ Chronic disease } \\
\hline At least one chronic condition & 2558 & 39.1 \\
\hline 1 Chronic condition & 1873 & 28.6 \\
\hline$\geq 2$ Chronic conditions & 685 & 10.5 \\
\hline \multicolumn{3}{|l|}{ Mental health symptom* } \\
\hline 1 symptom & 1897 & 29.0 \\
\hline$\geq 2$ symptoms & 2903 & 44.3 \\
\hline \multicolumn{3}{|l|}{ Social relation $^{*}$} \\
\hline$\geq 1$ poor relationships & 1278 & 19.5 \\
\hline \multicolumn{3}{|c|}{ Chronic disease, mental health symptom and poor social relation combined ${ }^{*}$} \\
\hline One present & 2626 & 41.1 \\
\hline Two present & 2224 & 34.8 \\
\hline All three present & 496 & 7.8 \\
\hline \multicolumn{3}{|l|}{ Appetite $^{*}$} \\
\hline Good & 3978 & 60.6 \\
\hline Fair & 2446 & 37.3 \\
\hline Poor & 140 & 2.1 \\
\hline \multicolumn{3}{|l|}{ Sleep quality ${ }^{\star}$} \\
\hline Good & 3428 & 52.3 \\
\hline Fair & 2650 & 40.5 \\
\hline Poor & 472 & 7.2 \\
\hline \multicolumn{3}{|l|}{ Dependent on medication ${ }^{*}$} \\
\hline Not at all or seldom & 4476 & 68.3 \\
\hline Sometimes & 868 & 13.3 \\
\hline Often or always & 1205 & 18.4 \\
\hline \multicolumn{3}{|l|}{ Activity limitation* } \\
\hline Doing housework & 3775 & 57.6 \\
\hline Stair-climbing & 3592 & 54.8 \\
\hline Stooping, kneeling or crouching & 3288 & 50.2 \\
\hline Walking & 3536 & 54.0 \\
\hline 1 limitation & 613 & 9.4 \\
\hline$\geq 2$ limitations & 3758 & 57.4 \\
\hline
\end{tabular}

Table 2. Prevalence of reported health conditions $(n=6551) .{ }^{\star}$ Data of some participants were missing.

Figure 1 shows the number and proportion of participants with various physical diseases, psychological states, and social relationships. Hypertension (27.7\%), poor memory (62.7\%) and poor neighbor relationships (14.9\%) were the most commonly reported problems.

Association between self-rated health and chronic disease, mental health symptoms, and poor social relationships. The bivariate analysis showed that, compared with participants who reported good self-rated health, those who reported poor self-rated health had a higher prevalence of chronic disease (52.8\% vs. $21.2 \%, P<0.001)$, mental health symptoms $(87.9 \%$ vs. $58.5 \%, P<0.001)$, poor social relationships ( $26.8 \%$ vs. $10.2 \%, P<0.001$ ), and the co-occurrence of chronic disease, mental health symptoms, and poor social relationships $(12.4 \%$ vs. $1.7 \%, P<0.001)$. Poor self-rated health was significantly associated with the three leading chronic conditions (i.e., hypertension, diabetes and heart disease), mental health symptoms (feeling unsatisfied with life, feeling low or depressed, poor memory and being unable to concentrate for $10 \mathrm{~min}$ ) and poor social relationships (with family, friends, and neighbors) (Ps $<0.05)$ (Table 3).

The logistic regression models, which included self-rated health (good vs. poor) as the dependent variable, demonstrated that poor self-rated health, after adjusting for other background characteristics, was significantly associated with chronic disease, mental health symptoms, and poor social relations $(\mathrm{Ps}<0.05)$. The probability of poor self-rated health was higher among individuals with more than one chronic disease, mental health symptoms, and poor social relationships (odds ratio (OR): 4.27, 95\% confidence interval (CI): 3.24-5.62; 2.75, 2.31-3.29; and 1.35, 1.13-1.62, respectively). In addition, poor economic conditions (OR 1.53; 95\% CI: 1.30-1.79), poor housing conditions $(1.78 ; 1.15-2.77)$, poor appetite $(3.84 ; 1.82-8.12)$, poor sleep $(1.95 ; 1.46-2.61)$, medication dependence $(3.51 ; 2.82-4.37)$, and activity limitations $(2.17 ; 1.87-2.52)$ were significantly associated with 


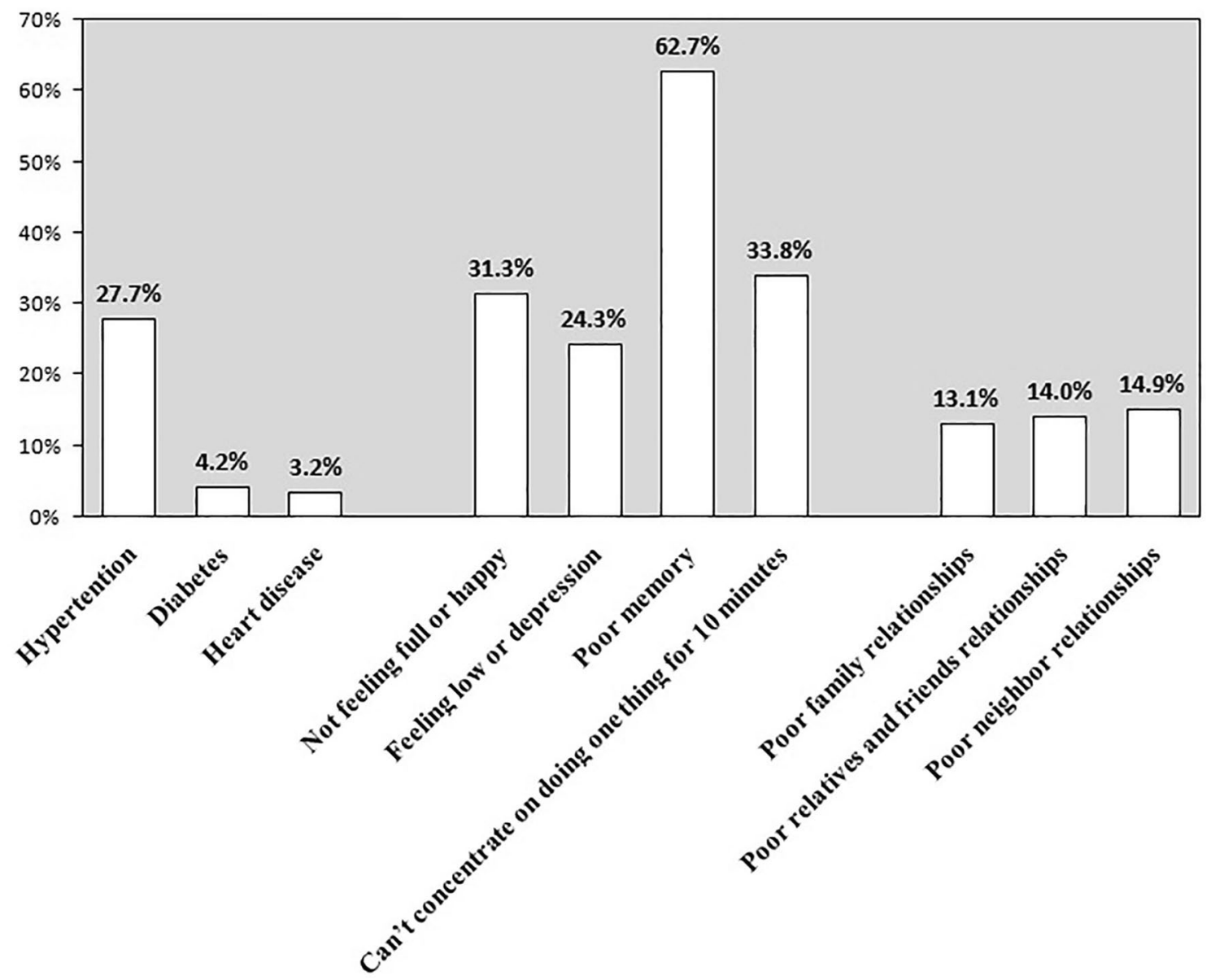

Figure 1. Proportion of chronic diseases, mental health symptoms and poor social relations among the participants.

poor self-rated health, whereas participants with "a secondary or higher" education level $(0.79 ; 0.64-0.97)$ and those who "lived alone" $(0.73 ; 0.57-0.93)$ were significantly associated with good self-rated health (Table 4).

The results of the logistic regression models, which included self-rated health (good vs. poor) as the dependent variable also demonstrated that, compared with participants who reported good self-rated health, those who reported a co-occurrence of chronic disease, mental health symptoms, and poor social relationships were significantly more likely to report poor self-rated health. In addition, from the first factor onward, a cumulative and negative correlation was found between co-occurring multimorbidity and with self-rated health (OR of one present: 2.35, 95\% CI: 1.92-2.87; two present: 5.04, 4.04-6.28; three present: 8.47, 5.76-12.45). The association of the background characteristics with self-rated health was the same as that reported in Table 4 (Table 5).

\section{Discussion}

Using a large representative sample with a high response rate, the present study demonstrated that a significant association between poor self-rated health and participants who experienced chronic diseases, mental health symptoms, and poor social relationships. The probability of reporting poor self-rated health was higher among participants who experienced more than one chronic disease, mental health symptoms, and poor social relationships. Participants who experienced the co-occurrence of chronic diseases, mental health symptom, and poor social relationships were significantly more likely to report poor self-rated health, and from the first factor onward, co-occurring multimorbidity was cumulatively and negatively correlated with self-rated health among the older population.

In this study population, the prevalence of chronic diseases, mental health symptoms, and poor social relationships was $39.1 \%, 73.3 \%$, and $19.5 \%$ respectively. Moreover, the co-occurrence of two and three problems (i.e., chronic diseases, mental health symptoms and poor social relationships) was $34.8 \%$ and $7.8 \%$, respectively. A study carried out in Denmark showed that $47.6 \%$ of older people aged 60-74 years old reported no chronic diseases, and clinical assessments revealed that $30.2 \%$ of the participants suffered from none of the chronic diseases investigated ${ }^{13}$. St John et al. found that among adults aged 65 years or older in Canada, $13.3 \%$ of those living in urban areas and $8.9 \%$ of those living in rural regions developed depressive symptoms ${ }^{10}$. The current study showed a relatively low rate of reported chronic diseases and a high rate of mental health symptoms. The low prevalence of self-reported chronic diseases may be due to the low education level of the participants, a limited 


\begin{tabular}{|c|c|c|c|}
\hline & \multicolumn{2}{|c|}{ Self-rated health } & \multirow[b]{2}{*}{ OR $(95 \% C I)$} \\
\hline & Good (\%) & Poor (\%) & \\
\hline \multicolumn{4}{|l|}{ No of chronic diseases } \\
\hline 0 & $2248(78.8)$ & $1745(47.2)$ & 1.00 \\
\hline 1 & $506(17.7)$ & $1367(37.0)$ & $3.48(3.09-3.92)^{* *}$ \\
\hline$\geq 2$ & $99(3.5)$ & $586(15.8)$ & $7.63(6.11-9.52)^{* *}$ \\
\hline \multicolumn{4}{|l|}{ No of mental health symptoms } \\
\hline 0 & $1152(41.5)$ & $436(12.1)$ & 1.00 \\
\hline 1 & $914(32.9)$ & $983(27.2)$ & $2.84(2.47-3.28)^{* *}$ \\
\hline$\geq 2$ & $712(25.6)$ & $2191(60.7)$ & $8.13(7.08-9.34)^{* *}$ \\
\hline \multicolumn{4}{|l|}{ No of poor social relations } \\
\hline 0 & $2557(89.8)$ & $2705(73.2)$ & 1.00 \\
\hline$\geq 1$ & $290(10.2)$ & $988(26.8)$ & $3.22(2.80-3.71)^{* *}$ \\
\hline \multicolumn{4}{|c|}{ No of chronic disease, mental health symptomand poor social relation combined } \\
\hline None present & $876(31.6)$ & $170(4.7)$ & 1.00 \\
\hline One present & $1353(48.8)$ & $1265(35.1)$ & $4.82(4.02-5.78)^{\star *}$ \\
\hline Two present & $497(17.9)$ & $1725(47.8)$ & $17.89(14.76-21.68)^{* *}$ \\
\hline Three present & $47(1.7)$ & $448(12.4)$ & $49.12(34.87-69.18)^{* *}$ \\
\hline \multicolumn{4}{|l|}{ Chronic disease $^{\#}$} \\
\hline Hypertension & $428(15.0)$ & $1387(37.5)$ & $3.40(3.01-3.84)^{* *}$ \\
\hline Diabetes mellitus & $48(1.7)$ & $228(6.2)$ & $3.84(2.80-5.26)^{* *}$ \\
\hline Cardiac disease & $29(1.0)$ & $182(4.9)$ & $5.04(3.40-7.48)^{* *}$ \\
\hline \multicolumn{4}{|l|}{ Mental health symptom ${ }^{\#}$} \\
\hline Not feeling satisfied with life & $448(15.7)$ & $1604(43.4)$ & $4.11(3.65-4.64)^{* *}$ \\
\hline Feeling downhearted or depressed & $396(13.9)$ & $1196(32.4)$ & $2.97(2.61-3.37)^{* *}$ \\
\hline Poor memory & $1271(45.6)$ & $2834(78.3)$ & $4.30(3.85-4.79)^{* *}$ \\
\hline Can't concentrate on doing one thing for $10 \mathrm{~min}$ & $559(19.6)$ & $1653(44.8)$ & $3.33(2.97-3.72)^{* *}$ \\
\hline \multicolumn{4}{|l|}{ Social relation ${ }^{\#}$} \\
\hline Poor family relationships & $155(5.4)$ & $706(19.1)$ & $4.11(3.43-4.92)^{* *}$ \\
\hline Poor friends relationships & $171(6.0)$ & $746(20.2)$ & $3.97(3.33-4.72)^{* *}$ \\
\hline Poor neighbor relationships & $194(6.8)$ & $784(21.2)$ & $3.69(3.13-4.35)^{* *}$ \\
\hline
\end{tabular}

Table 3. Bivariate analysis for relationship of chronic disease, mental health symptom and poor social relation with self-rated health. ${ }^{*}$ Both counts and percentages are based upon weighted inputted values. ${ }^{* *}$ The reference category is subjects without the specified condition, $P<0.01$.

knowledge of diseases, and a reluctance to report illness. The high rate of mental health symptoms was likely due to the data collection methodology used in this study, such as the inclusion of memory and concentration, as well as the general mental health symptom, such as depression or anxiety symptoms.

In the present study, the prevalence of poor self-rated health was $56.4 \%$. Reports of poor self-rated health among older people varies among different studies. For example, a study conducted in Spain found that $39.7 \%$ of older people aged 65 years old and over reported positive self-rated health ${ }^{14}$. In another study of 185 communitydwelling Icelanders aged $65-88$ years old, $45 \%$ rated their health as good, $37 \%$ reported fair or poor health, and $18 \%$ stated that their health was very good or excellent ${ }^{3}$. In China, a study revealed that $68.0 \%$ of middle-aged and older people (aged 50 to 70 years) in Beijing and Shanghai reported poor or fair self-rated health ${ }^{15}$.

According to the World Health Organization (WHO) definition, health is a state of complete physical, mental and social well-being, and it does not merely describe the absence of disease or infirmity ${ }^{16}$. Correspondingly, we included all of the three critical dimensions of health in our analyses, namely, self-rated chronic diseases, mental health symptoms and social relationships. The absence of chronic diseases is a key measure of successful aging ${ }^{17}$. Our results showed that, chronic diseases, and the presence of one or more chronic diseases, in particular, were a significant predictor of poor self-rated health. This result is similar to the findings of previous studies, both in China and beyond ${ }^{5,18}$. Our results also revealed that self-rated health was strongly associated with mental health symptoms and poor social relationships, after adjusting for sociodemographic variables, living arrangements, sleep quality, medication, and activity limitations. A recent study which investigated community-dwelling Icelanders aged 65-88 years old also found a robust relationship between poor self-rated health and depressive symptoms adjusting for gender ${ }^{3}$. Another study found an association between low social network involvement and poor self-rated health among older men, whereas perceptions of low social support were associated with poor self-rated health among older women ${ }^{19}$. An association was also found between poor self-rated health and social capital, such as a lack of personal support and the absence of experiences that caused the participants to feel a sense of pride, even after controlling for prominent health-related factors including disability pensions, ethnicity, and financial stress ${ }^{20}$. 


\begin{tabular}{|c|c|c|c|c|}
\hline & Model 1 & Model 2 & Model 3 & Model 4 \\
\hline & OR(95\% CI) & OR(95\% CI) & OR(95\% CI) & OR(95\% CI) \\
\hline \multicolumn{5}{|l|}{ No of chronic diseases } \\
\hline 0 & 1.00 & 1.00 & 1.00 & 1.00 \\
\hline 1 & $3.73(3.27-4.26)^{* *}$ & $4.05(3.53-4.65)^{* *}$ & $4.18(3.64-4.80)^{* *}$ & $2.67(2.27-3.15)^{\star *}$ \\
\hline$\geq 2$ & $7.23(5.72-9.15)^{* *}$ & $7.92(6.22-10.09)^{\star *}$ & $8.31(6.52-10.59)^{* *}$ & $4.27(3.24-5.62)^{* *}$ \\
\hline \multicolumn{5}{|c|}{ No of mental health symptoms } \\
\hline 0 & 1.00 & 1.00 & 1.00 & 1.00 \\
\hline 1 & $2.60(2.24,3.03)^{\star *}$ & $2.33(1.99-2.72)^{\star *}$ & $2.32(1.98-2.71)^{* *}$ & $1.80(1.52-2.13)^{\star *}$ \\
\hline$\geq 2$ & $6.79(5.85,7.88)^{\star *}$ & $5.42(4.63-6.34)^{* *}$ & $5.20(4.43-6.09)^{* *}$ & $2.75(2.31-3.29)^{\star *}$ \\
\hline \multicolumn{5}{|c|}{ No of poor social relations } \\
\hline 0 & 1.00 & 1.00 & 1.00 & 1.00 \\
\hline$\geq 1$ & $2.36(2.01,2.77)^{\star *}$ & $1.95(1.65-2.30)^{* *}$ & $1.84(1.55-2.18)^{* *}$ & $1.35(1.13-1.62)^{\star *}$ \\
\hline \multicolumn{5}{|l|}{ Age group (year) } \\
\hline $60-69$ & & 1.00 & 1.00 & 1.00 \\
\hline $70-79$ & & $1.09(0.95-1.25)$ & $1.11(0.96-1.27)$ & $0.89(0.75-1.03)$ \\
\hline$\geq 80$ & & $1.15(0.94-1.39)$ & $1.16(0.95-1.42)$ & $0.81(0.65-1.01)$ \\
\hline \multicolumn{5}{|l|}{ Sex } \\
\hline Male & & 1.00 & 1.00 & 1.00 \\
\hline Female & & $1.15(1.02-1.31)^{\star}$ & $1.16(1.02-1.31)^{\star}$ & $1.03(0.89-1.18)$ \\
\hline \multicolumn{5}{|l|}{ Marital status } \\
\hline Married & & 1.00 & 1.00 & 1.00 \\
\hline Unmarried & & $0.92(0.59-1.44)$ & $1.04(0.65-1.67)$ & $0.92(0.55-1.52)$ \\
\hline Widowed/divorced & & $0.91(0.78-1.05)$ & $0.96(0.82-1.13)$ & $0.93(0.79-1.11)$ \\
\hline \multicolumn{5}{|l|}{ Education level } \\
\hline Below primary school & & 1.00 & 1.00 & 1.00 \\
\hline Primary & & $0.98(0.85-1.13)$ & $0.98(0.84-1.13)$ & $0.95(0.81-1.12)$ \\
\hline Secondary and higher & & $0.87(0.72-1.06)$ & $0.88(0.73-1.07)$ & $0.79(0.64-0.97)^{\star}$ \\
\hline \multicolumn{5}{|l|}{ Economic conditions } \\
\hline Good & & 1.00 & 1.00 & 1.00 \\
\hline Fair & & $2.48(2.18-2.81)^{* *}$ & $1.85(1.60-2.15)^{* *}$ & $1.53(1.30-1.79)^{* *}$ \\
\hline Poor & & $3.07(2.43-3.89)^{* *}$ & $2.06(1.57-2.69)^{* *}$ & $1.74(1.30-2.33)^{\star *}$ \\
\hline \multicolumn{5}{|l|}{ Housing conditions } \\
\hline Good & & & 1.00 & 1.00 \\
\hline Fair & & & $1.82(1.57-2.11)^{* *}$ & $1.65(1.41-1.94)^{* *}$ \\
\hline Poor & & & $1.96(1.31-2.94)^{* *}$ & $1.78(1.15-2.77)^{\star *}$ \\
\hline \multicolumn{5}{|l|}{ Living arrangement } \\
\hline With other person(s) & & & 1.00 & 1.00 \\
\hline Alone & & & $0.74(0.59-0.93)^{\star}$ & $0.73(0.57-0.93)^{\star}$ \\
\hline \multicolumn{5}{|l|}{ Appetite } \\
\hline Good & & & & 1.00 \\
\hline Fair & & & & $2.15(1.84-2.51)^{\star *}$ \\
\hline Poor & & & & $3.84(1.82-8.12)^{* *}$ \\
\hline \multicolumn{5}{|l|}{ Sleep quality } \\
\hline Good & & & & 1.00 \\
\hline Fair & & & & $2.36(2.04-2.74)^{* *}$ \\
\hline Poor & & & & $1.95(1.46-2.61)^{* *}$ \\
\hline \multicolumn{5}{|l|}{ Dependent on medication } \\
\hline Not at all or seldom & & & & 1.00 \\
\hline Sometimes & & & & $2.60(2.10-3.22)^{\star *}$ \\
\hline Often or always & & & & $3.51(2.82-4.37)^{* *}$ \\
\hline \multicolumn{5}{|l|}{ No of activity limitations } \\
\hline 0 & & & & 1.00 \\
\hline 1 & & & & $1.48(1.18-1.86)^{\star *}$ \\
\hline$\geq 2$ & & & & $2.17(1.87-2.52)^{* *}$ \\
\hline
\end{tabular}

Table 4. Multivariate analysis of the relationship of chronic disease, mental health symptom and poor social relation with self-rated health. ${ }^{*}$ The reference category is subjects without the specified condition, $P<0.05$. ${ }^{*}$ The reference category is subjects without the specified condition, $P<0.01$. 


\begin{tabular}{|c|c|c|c|c|}
\hline & Model 1 & Model 2 & Model 3 & Model 4 \\
\hline & OR(95\% CI) & OR(95\% CI) & OR(95\% CI) & OR(95\% CI) \\
\hline \multicolumn{5}{|c|}{ No of chronic disease and mental symptom and poor social relation combined } \\
\hline None present & 1.00 & 1.00 & 1.00 & 1.00 \\
\hline One present & $4.82(4.02-5.78)^{* *}$ & $4.11(3.42-4.95)^{* *}$ & $4.04(3.36-4.87)^{\star *}$ & $2.35(1.92-2.87)^{\star *}$ \\
\hline Two present & $17.89(14.76-21.68)^{* *}$ & $14.48(11.88-17.64)^{* *}$ & $14.25(11.68-17.39)^{* *}$ & $5.04(4.04-6.28)^{* \star}$ \\
\hline Three present & $49.12(34.87-69.18)^{\star *}$ & $33.15(23.36-47.03)^{* *}$ & $31.80(22.36-45.22)^{* *}$ & $8.47(5.76-12.45)^{* *}$ \\
\hline \multicolumn{5}{|l|}{ Age group (year) } \\
\hline $60-69$ & & 1.00 & 1.00 & 1.00 \\
\hline $70-79$ & & $1.16(1.01-1.33)^{*}$ & $1.18(1.03-1.35)^{*}$ & $0.90(0.77-1.05)$ \\
\hline$\geq 80$ & & $1.33(1.10-1.60)^{* *}$ & $1.34(1.10-1.62)^{* *}$ & $0.86(0.69-1.07)$ \\
\hline \multicolumn{5}{|l|}{ Sex } \\
\hline Male & & 1.00 & 1.00 & 1.00 \\
\hline Female & & $1.16(1.03-1.32)^{*}$ & $1.16(1.03-1.32)^{*}$ & $1.03(0.89-1.18)$ \\
\hline \multicolumn{5}{|l|}{ Marital status } \\
\hline Married & & 1.00 & 1.00 & 1.00 \\
\hline Unmarried & & $0.90(0.58-1.40)$ & $1.03(0.65-1.64)$ & $0.92(0.55-1.52)$ \\
\hline Widowed/divorced & & $0.94(0.81-1.09)$ & $1.00(0.86-1.17)$ & $0.96(0.81-1.14)$ \\
\hline \multicolumn{5}{|l|}{ Education level } \\
\hline Below primary school & & 1.00 & 1.00 & 1.00 \\
\hline Primary & & $0.98(0.85-1.13)$ & $0.98(0.84-1.13)$ & $0.95(0.81-1.11)$ \\
\hline Secondary and higher & & $0.88(0.73-1.06)$ & $0.90(0.74-1.09)$ & $0.79(0.64-0.98)^{\star}$ \\
\hline \multicolumn{5}{|l|}{ Economic conditions } \\
\hline Good & & 1.00 & 1.00 & 1.00 \\
\hline Fair & & $2.39(2.12-2.70)^{* *}$ & $1.80(1.56-2.07)^{* *}$ & $1.51(1.29-1.76)^{* *}$ \\
\hline Poor & & $3.27(2.61-4.10)^{* *}$ & $2.20(1.69-2.86)^{\star \star}$ & $1.79(1.34-2.38)^{\star *}$ \\
\hline \multicolumn{5}{|l|}{ Housing conditions } \\
\hline Good & & & 1.00 & 1.00 \\
\hline Fair & & & $1.76(1.53-2.03)^{* *}$ & $1.61(1.37-1.88)^{* *}$ \\
\hline Poor & & & $1.88(1.26-2.79)^{* *}$ & $1.71(1.11-2.64)^{*}$ \\
\hline \multicolumn{5}{|l|}{ Living arrangement } \\
\hline With other person(s) & & & 1.00 & 1.00 \\
\hline Alone & & & $0.72(0.58-0.90)^{* *}$ & $0.70(0.55-0.90)^{\star *}$ \\
\hline \multicolumn{5}{|l|}{ Appetite } \\
\hline Good & & & & 1.00 \\
\hline Fair & & & & $2.12(1.82-2.47)^{\star \star}$ \\
\hline Poor & & & & $3.50(1.67-7.34)^{\star *}$ \\
\hline \multicolumn{5}{|l|}{ Sleep quality } \\
\hline Good & & & & 1.00 \\
\hline Fair & & & & $2.34(2.02-2.71)^{* *}$ \\
\hline Poor & & & & $2.08(1.56-2.77)^{\star *}$ \\
\hline \multicolumn{5}{|c|}{ Dependent on medication } \\
\hline Not at all or seldom & & & & 1.00 \\
\hline Sometimes & & & & $2.94(2.39-3.62)^{\star *}$ \\
\hline Often or always & & & & $4.45(3.64-5.45)^{* *}$ \\
\hline \multicolumn{5}{|l|}{ No of activity limitations } \\
\hline 0 & & & & 1.00 \\
\hline 1 & & & & $1.42(1.14-1.77)^{\star *}$ \\
\hline$\geq 2$ & & & & $2.26(1.96-2.62)^{\star *}$ \\
\hline
\end{tabular}

Table 5. Multivariate analysis of the relationship of co-occurrence of chronic disease and mental health symptom and poor social relation with self-rated health. ${ }^{\star}$ The reference category is subjects without the specified condition, $P<0.05$. ${ }^{*}$ The reference category is subjects without the specified condition, $P<0.01$.

In this study, the most significant finding was the association between self-rated health and the co-occurrence of chronic disease, mental health symptoms, and poor social relationships, as this association was the strongest and it was independent. It is notable that older people who experienced multiple chronic diseases, mental 
health symptoms and poor social relationships reported poor self-rated health. The social relationships may not directly describe health status, but they influence the likelihood of different objective health conditions being used as a basis for self-ratings. In line with the views of WHO, the findings of the current study highlighted the multidimensionality of health. Our results are also consistent with previous studies. Sheridan et al. found that coexisting chronic conditions and high depressive symptoms were associated with a higher probability of reported prospective disability in relation to daily living activities and poor self-rated health ${ }^{21}$. The results of Quiñones et al. showed a combination of depression and/or cognitive impairment with multimorbidity was associated with a substantially higher risk of prospective disability than that observed in the case of a combination of somatic conditions only ${ }^{22}$. A study carried out among older Chinese Americans showed that family cohesion and support moderated the relationship between acculturation and self-rated health, and family members and family support were associated with well-being ${ }^{23}$. By employing a large sample population-based study and controlling for a wide range of background characteristics, this study contextualized and elucidated the above conclusions. Most importantly, our findings highlighted the potential multiplicative effect of co-occurring multimorbidity, mental health symptoms, and poor social relationships on poor self-rated health.

The role of age and sex in self-health evaluations remains controversial. In contrast with the findings of some previous studies, we found no evidence of a significant correlation between age, sex, and self-rated health ${ }^{5,14}$. However, our results are in line with another study, which found that the self-rated health of older people aged over 56 years old was not affected by age or gender ${ }^{24}$. Moreover, we found that participants who lived alone reported good self-rated health, while participants who experienced activity-related limitations reported poor self-rated health. This result seems reasonable, because older people who have no mobility limitations and who perceive their health as good tend to live alone (independently). It can be expected that older people who live alone in the community represent a sample of healthier people. The results also highlighted that people who live autonomously and independently rated their health more positively, regardless of access to family support and social agencies ${ }^{25}$. We found a significant correlation between poor appetite and self-rated health. Poor appetite is a common problem among older people. It can contribute to weight loss and, nutritional deficiencies, and is associated with poor healthcare outcomes, including increased morbidity and mortality ${ }^{26}$. Although a reduction in energy intake is largely due to physiological changes that occur as a result of the ageing process, it may predispose older people to psychological symptoms (e.g., depression), social issues (e.g., poverty, loneliness and social isolation), and physical problems (e.g., common medical conditions and medication dependence) ${ }^{27}$. The findings of the current also confirmed some well-established risk factors of self-rated health, including poor economic conditions, poor housing conditions, poor sleep, and a low education level.

Collectively, the results of this study provide several novel insights into the association between self-rated health and the co-occurrence of chronic diseases, mental health symptoms and poor social relationship. Our results highlighted the importance of detecting and managing chronic diseases, mental health symptoms and social relationships among older people, as well as the co-occurrence for improving the health outcomes of this population.

Several limitations in this study warrant further comment. The data related to mental health, cognition, and activity-related limitations were obtained using the self-reporting method, rather than referring to the diagnoses of clinicians or clinical diagnostic scales. The self-reported nature of all of the data may have introduced response bias. However, the results of the internal consistency analysis of the questionnaire showed that the questionnaire had good reliability, and Cronbach's alpha for mental health symptoms, poor social relationships, and activity-related limitation were $0.826,0.884$ and 0.915 , respectively. Although some older people declined to take part in this study, the response rate was high. Therefore, we do not believe that the results were affected by non-respondents.

\section{Conclusion}

Our research further identified that the co-occurrence of chronic diseases, mental health symptoms, and poor social relationships was associated with poor self-rated health, while co-occurring multimorbidity, mental health symptoms, and poor social relationships were cumulatively and negatively correlated with self-rated health. It is essential to develop specific interventions targeting lifestyle patterns, mental health and social relationships to prevent chronic morbidity and improve older people's perceived health.

\section{Methods}

Sampling and recruitment. In this study, the sample included participants from the community health surveillance which was conducted in Zhongshan city in Guangdong, China, in 2011. The surveillance, which was carried out every 5 years, was cross-sectional with representative samples, and it therefore facilitated a better understanding of the major health problems and their related factors.

The participants were selected on the basis of the following criteria: (1) 60 years or older; (2) held permanent household registration in Zhongshan city; (3) were living in Zhongshan city when the study was carried out; and (4) were able to answer questions or complete the questionnaire independently.

A multistage sampling method was employed to select a representative sample of residents. The sampling frame was based on the household registration system. First, 30\% of the districts/towns were randomly sampled from all 24 districts/towns in Zhongshan city. Second, 30\% of the streets/villages were randomly sampled from each selected district/town. Then, $50 \%$ of the families were randomly sampled from each selected street/village. To guarantee an adequate sample size, a replacement method was adopted. In the event that a sampled family could not be contacted after three attempts, the nearest family was selected as substitute. A total of 19,086 households were recruited, with a substitution rate of $9.4 \%$. The final sample included 43,028 participants, of which 7,029 
were aged 60 years old or over. Among these 7,029 older participants, 6,551 completed the survey, including $3,539(54.0 \%)$ males and 3,012 (46.0\%) females. The response rate was $93.2 \%$.

The study was approved by the research ethics review committee of Guangzhou Medical University. Written informed consents were obtained from all participants. All research processes were performed in accordance with the requirements of the ethics committee.

Data collection. The researchers carried out home visits to approach the participants who were then requested to complete a one-on-one face-to-face interview using structured questionnaires. Data related to the participants' demographics, socioeconomic status, self-rated health, chronic diseases, psychological states, social relationships, medication, and activity limitations were collected. The internal consistency analysis of the questionnaire showed that the questionnaire had good reliability, and Cronbach's alpha for mental health symptoms, poor social relationships, and activity-related limitation were $0.826,0.884$ and 0.915 , respectively. The interviewers included undergraduate or postgraduate (master's) students at Guangzhou Medical University. Standard procedures were established to guide the recruitment, training, and supervision of the interviewers.

Self-rated health was measured by posing the following question: "During the past 4 weeks, how would you rate your health? Would you say, very good, good, fair, bad or very bad?". Among 6551 participants completed the surveys, 441 (6.7\%), $2412(36.8 \%), 3060$ (46.7\%), $598(9.1 \%)$ and $40(0.6 \%)$ reported very good, good, fair, bad and very bad, respectively. The responses were collapsed into two categories, i.e., good (very good, good) and poor (fair, bad, very bad) ${ }^{28}$.

Information concerning chronic conditions was obtained using a checklist of chronic illnesses extracted from the International Diseases Classification (ICD-10), which included 300 common diseases. Participants were asked whether they have ever been diagnosed by a registered medical doctor as having of the stated physical health problems. If the participant's illness did not on the list, the name of the specific illness was recorded.

The mental health status of the participants was measured by posing the following 4 questions: "Did you consider your life as happy and fulfilling in the past four weeks?" (Possible answers: 1 all the time/2 most of the time/3 sometimes/4 occasionally/5 never); "Did you feel downhearted or depressed in the past four weeks?" (Possible answers: 1 never/ 2 occasionally/3 sometimes/4 most of the time/5 all the time); "How has your memory been during the past four weeks" (Possible answers: 1 very good/2 good/ 3 fair $/ 4$ bad $/ 5$ very bad); and "Were you able to concentrate on whatever you were doing for $10 \mathrm{~min}$ in the past 4 weeks?" (Possible answers: 1 all the time/2 most of the time $/ 3$ sometimes/4 occasionally/5 never). The responses were collapsed into two categories, i.e., "absence of mental health symptoms" (" 1 " or " 2 ") and "presence of mental health symptoms" (“3", " 4 ", or " 5 ").

Social relationships were measured by posing the following 3 questions: "During the past 4 weeks, how would you describe your relationship with your family/friends/neighbors?" (Possible answers: very good/good /fair/ $\mathrm{bad} /$ very bad). The responses were collapsed into two categories, i.e., favorable relationship (good, very good) and unfavorable relationship (fair, bad, very bad).

Activity-related limitations were measured by posing the following 4 questions: "During the past four weeks, did your health ever limit you in terms of these activities? If so, to what extent? Such activities included "riding a bike or doing homework for more than one hour", "climbing three floors of stairs", "bending, kneeling, or stooping", "walking more than a mile". The possible answers included the following: 1 not at all limited /2 limited a little $/ 3$ moderately limited / 4 substantially limited $/ 5$ completely limited). The responses were collapsed into two categories: non-limitation ("1") and limitation (“2", "3", “4”, or "5").

Dependence on medical care was determined by posing the question "Are you currently taking medication or receiving medical treatment to help you carry out your daily life?" (Possible answers: not at all/ seldom/ sometimes/ often/ always). The responses were collapsed into three categories, i.e., not at all or seldom, sometimes, often or always. Sleep quality and appetite were assessed by posing the question, "How would you rate your sleep/appetite? Would you say, very good, good, fair, bad or very bad?" The responses were collapsed into three categories, i.e., good (very good, good), fair, and poor (bad, very bad).

Demographic and socioeconomic characters included age, sex, education (below primary school, primary school, secondary and higher), marital status (single, married, separated/ divorced/ widowed), living arrangements [living alone, living with other person(s)], and self-reported economic conditions and housing conditions (very good/ good /fair/ poor/ very poor). The responses were collapsed into three categories, i.e., good (very good, good), fair and poor (poor, very poor).

Data analysis. The sample size was calculated according to the prevalence of the co-occurrence of physical, mental, and social problems among older people. On the basis of our exploratory research, the prevalence of the co-occurrence of physical health problems among older people was about $6.0 \%$, and the sample size included 6,267 participants with a significance level of $5 \%$.

The data included the mean and standard deviation continuous variables, and the frequency (\%) of categorical variables. We constructed a series of hierarchical models using logistic regression analysis, with self-rated health as the dependent variable. The number of self-reported chronic diseases, mental health symptoms and poor social relationships, as well as their co-occurrence, were entered separately in step 1 (Model 1) and the demographic variables were entered in step 2 (Model 2). Housing conditions, living arrangement, appetite, sleep, medication, and activity-related limitations were entered sequentially in Model 3 and Model 4 in order to assess the unique contribution of each factor to self-rated health. The variables were selected by a step-wise method. $P<0.05$ with a $95 \%$ CI of OR that excluded the null value of 1 was considered statistically significant. All analyses were conducted with SPSS 22.0 (SPSS Inc., Chicago, IL). 


\section{Data availability}

The datasets generated and/or analyzed during the current study are available from the corresponding author on reasonable request.

Received: 5 February 2020; Accepted: 24 June 2021

Published online: 19 July 2021

\section{References}

1. Jylhä, M. What is self-rated health and why does it predict mortality? Towards a unified conceptual model. Soc. Sci. Med. 69(3), 307-316 (2009).

2. Tamayo-Fonseca, N. et al. Self-rated health and mortality: A follow-up study of a Spanish population. Public Health 127(12), $1097-1104(2013)$

3. Arnadottir, S. A., Gunnarsdottir, E. D., Stenlund, H. \& Lundin-Olsson, L. Determinants of self-rated health in old age: a populationbased, cross-sectional study using the International Classification of Functioning. BMC Public Health 11, 670 (2011).

4. Supranowicz, P. et al. Determinants of self-rated health of Warsaw inhabitants. Rocz. Panstw. Zakl. Hig. 63(3), 273-284 (2012).

5. Dong, W. et al. Determinants of self-rated health among shanghai elders: a cross-sectional study. BMC Public Health 17(1), 807 (2017).

6. Zhu, C. et al. Association of somatic symptoms with depression and anxiety in clinical patients of general hospitals in Guangzhou, China. Gen. Hosp. Psychiatry 34(2), 113-120 (2012).

7. Wang X, Peng C. A study on the trends of the characteristics of the elderly population in China. Population and Society 36(4), 29-45 (2020)

8. Wang, S. et al. Poor mental health status and its associations with demographic characteristics and chronic diseases in Chinese elderly. Soc. Psychiatry Psychiatr. Epidemiol. 51(10), 1449-1455 (2016).

9. Galenkamp, H., Braam, A. W., Huisman, M. \& Deeg, D. J. Somatic multimorbidity and self-rated health in the older population. J. Gerontol. B Psychol. Sci. Soc. Sci. 66(3), 380-386 (2011).

10. St John, P. D., Blandford, A. A. \& Strain, L. A. Does a rural residence predict the development of depressive symptoms in older adults?. Can. J. Rural Med. 14, 150-156 (2009).

11. Ahmad, B. et al. The influence of neighbourhood formality status and socio-economic position on self-rated health among adult men and women: A multilevel, cross sectional, population study from Aleppo, Syria. BMC Public Health 13, 233 (2013).

12. Zhu, C. et al. Self-rated chronic conditions and 2-week prevalence in adults in Zhongshan, China: An epidemiological survey. BMJ Open 5(11), e008441 (2015).

13. Frost, M. et al. Chronic diseases in elderly men: underreporting and underdiagnosis. Age Ageing 41(2), 177-183 (2012).

14. Girón, P. Is age associated with self-rated health among older people in Spain?. Cent. Eur. J. Public Health 20(3), 185-190 (2012).

15. Haseli-Mashhadi, N. et al. Self-rated health in middle-aged and elderly Chinese: Distribution, determinants and associations with cardio-metabolic risk factors. BMC Public Health 9, 368 (2009).

16. Callahan, D. The WHO definition of "Health". Stud. Hastings Cent. 1(3), 77-88 (1973).

17. Fontana, L. \& Hu, F. B. Optimal body weight for health and longevity: Bridging basic, clinical, and population research. Aging Cell 13(3), 391-400 (2014)

18. Meng, Q., Xie, Z. \& Zhang, T. A single-item self-rated health measure correlates with objective health status in the elderly: A survey in suburban Beijing. Front. Public Health 2, 27 (2014).

19. Caetano, S. C., Silva, C. M. \& Vettore, M. V. Gender differences in the association of perceived social support and social network with self-rated health status among older adults: A population-based study in Brazil. BMC Geriatr. 13, 122 (2013).

20. Lindén-Boström, M., Persson, C. \& Eriksson, C. Neighbourhood characteristics, social capital and self-rated health-a populationbased survey in Sweden. BMC Public Health 10, 628 (2010).

21. Sheridan, P. E., Mair, C. A. \& Quiñones, A. R. Associations between prevalent multimorbidity combinations and prospective disability and self-rated health among older adults in Europe. BMC Geriatr. 19(1), 198 (2019).

22. Quiñones, A. R. et al. Prospective disability in different combinations of somatic and mental multimorbidity. J. Gerontol. A Biol. Sci. Med. Sci. 73(2), 204-210 (2018).

23. Wang, K. et al. Self-rated health among older Chinese Americans: the roles of acculturation and family cohesion. J. Appl. Gerontol. 6, $733464819898316(2020)$.

24. Ramkumar, A. et al. Self-rated health, associated factors and diseases: A community-based cross-sectional study of Singaporean adults aged 40 years and above. Ann. Acad. Med. Singap. 38(7), 606-607 (2009).

25. Rueda, S., Artazcoz, L. \& Navarro, V. Health inequalities among the elderly in Western Europe. J. Epidemiol. Community Health 62(6), 492-498 (2008).

26. Pilgrim, A. L., Robinson, S. M., Sayer, A. A. \& Roberts, H. C. An overview of appetite decline in older people. Nurs. Older People 27(5), 29-35 (2015).

27. Donini, L. M., Savina, C. \& Cannella, C. Eating habits and appetite control in the elderly: the anorexia of aging. Int. Psychogeriatr. 15(1), 73-87 (2003).

28. Wang, K., Zhang, A., Sun, F. \& Hu, R. X. Self-rated health among older Chinese Americans: the roles of acculturation and family cohesion. J. Appl. Gerontol. https://doi.org/10.1177/0733464819898316 (2020).

\section{Acknowledgements}

We wish to thank medical students of Guangzhou Medical University for their kind assistance. This research was supported by the Science and Technology Fund of Guangzhou (201707010497).

\section{Author contributions}

C.Y.Z. directed the study implementation. H.L.Y. and Q.S.G. ${ }^{\Phi}$ analyzed and interpreted the data. X.L.G. reviewed the article. Q.D., Y.F.T., J.M., W.T.Y., Q.S.G. ${ }^{\Delta}$ and R.R. carried out acquisition of data, helped conduct the literature review (Q.S.G. ${ }^{\Phi}$ is the initial of Qingshan Geng. Q.S.G. ${ }^{\triangle}$ is the initial of Qiangsheng Gan).

\section{Competing interests}

The authors declare no competing interests.

\section{Additional information}

Correspondence and requests for materials should be addressed to C.Z. 
Reprints and permissions information is available at www.nature.com/reprints.

Publisher's note Springer Nature remains neutral with regard to jurisdictional claims in published maps and institutional affiliations.

(c) (i) Open Access This article is licensed under a Creative Commons Attribution 4.0 International License, which permits use, sharing, adaptation, distribution and reproduction in any medium or format, as long as you give appropriate credit to the original author(s) and the source, provide a link to the Creative Commons licence, and indicate if changes were made. The images or other third party material in this article are included in the article's Creative Commons licence, unless indicated otherwise in a credit line to the material. If material is not included in the article's Creative Commons licence and your intended use is not permitted by statutory regulation or exceeds the permitted use, you will need to obtain permission directly from the copyright holder. To view a copy of this licence, visit http://creativecommons.org/licenses/by/4.0/.

(C) The Author(s) 2021 